\title{
O USO DO CMS JOOMLA E SUAS FERRAMENTAS HIPERTEXTUAIS NA PRODUÇÃO DE SITES EDUCATIVOS E DE MATERIAL DIDÁTICO ONLINE
}

\author{
Marcos Antonio Pereira Coelho/Universidade Estadual do Norte Fluminense \\ Fabiana Aguiar de Miranda/Universidade Estadual do Norte Fluminense \\ Jeferson Cabral Azevedo/Universidade Estadual do Norte Fluminense \\ Joyce Vieira Fettermann/Universidade Estadual do Norte Fluminense \\ Carlos Henrique de Souza Medeiros/Universidade Estadual do Norte Fluminense \\ Daniella Costantini das Chagas Ribeiro/Universidade Estadual do Norte Fluminense
}

RESUMO: a necessidade de atualização dos conteúdos, os preços relativamente baixos dos provedores de acesso, dentre outros fatores, fazem com que, cada vez mais, empresas, escolas e outras instituições tenham o seu espaço na web. Uma escola que produza e disponibilize material com alguma regularidade terá necessidades que vão além de um blog. Seria necessário, então, criar redes de informações onde possam inserir, modificar e consultar os conteúdos com vistas a promover a interação direta com os alunos e a sociedade em geral. O presente artigo tem como objetivo apresentar as ferramentas hipertextuais do Sistema de Gestão de Conteúdos, Joomla, e suas ferramentas hipertextuais que podem ser utilizadas na produção de matérial didático online.

PALAVRAS-CHAVE: Gestão de conteúdo. Joomla. Hipertexto. Material didático.

\begin{abstract}
: the updating of the content and relatively low prices of service providers make more and more companies, schools and other institutions have their own space on the Web. Thus, a school that produces and makes available material on a regular basis will have needsthat go beyond a blog. It is therefore necessary to create networks of information, where they can enter, modify, and query information, promoting direct interaction with students and society in general. In this perspective, this article aims at presenting the tools of hypertext content management system, Joomla, seeking to guarantee a space for reflection and action, when used in education for teachers and students, as proposed interaction and on-line publication of their productions and learning content.
\end{abstract}

KEYWORDS: Content manegment. Joomla. Hipertext. Educational Material.

\section{INTRODUÇÃO}

Sabe-se que a Internet é hoje um meio de comunicação onde enviamos, recebemos e modificamos as informações. A necessidade de atualização dos conteúdos, os preços relativamente baixos dos provedores de acesso, dentre outros fatores, fazem com que, cada vez mais, empresas, escolas e outras entidades e instituições tenham o seu espaço na web. No entanto, nem todo 
conteúdo é atualizado com frequência ou é concebido de modo a facilitar o acesso às informações mais relevantes.

Embora seja fácil construir, conceber e, sobretudo, manter um sítio atualizado na web, devido às ferramentas disponíveis serem cada vez mais intuitivas, isto continua sendo uma tarefa que nem sempre se consegue concretizar com eficiência e qualidade.

Um professor que produza e queira disponibilizar material com alguma regularidade terá necessidades que irão além de construir um simples blog. Seria necessário, então, criar redes de informações onde os educadores pudessem inserir, modificar, consultar, fazer usos de ambientes virtuais de aprendizagem e participar de comunidades e redes sociais online, para promoverem, assim, a participação e interação direta dos alunos.

O Sistema de Gerenciamento de Conteúdo Joomla surge, nessa perspectiva, como uma solução para a gestão de conteúdos da web e a criação de portais educativos. O website do Ministério da Educação (<www.mec.gov.br>) e algumas universidades já estão utilizando essa tecnologia e adequando-a para a disponibilização de informações na internet.

O presente artigo descreve os planos de pesquisa de análise do CMS (Content Management System / Sistema de Gestão de Conteúdos) Joomla e suas ferramentas hipertextuais, buscando garantir um espaço de reflexão e ação acerca da formulação de propostas para verificação da eficácia dessa nova ferramenta quando utilizada na educação por professores e alunos como proposta de interação e publicação online de suas produções e conteúdos de aprendizagem.

\section{SISTEMAS DE GESTÃO DE CONTEÚDOS WEB (CMS - Content Management System)}

De acordo com Rahmel (2010), com o surgimento da internet, para se criar uma página na web, por mais simples que ela fosse, era necessário aprender a linguagem e programação HTML (Hypertext Markup Language) que consistia apenas em conteúdos estáticos. Desde então, houve uma evolução nos modelos de publicação e disseminação da informação através de sítios web.

Carvalho (2006), em um olhar sobre os sites ao longo de mais de uma década, identificou quatro fases que permitem verificar uma evolução na construção de sites não só ao nível do layout das páginas e da estruturação da informação, mas também, à integração de ferramentas de comunicação e de edição colaborativa online.

A primeira fase, designada como "Fase da informação corrida”, é assinalada pelo surgimento das primeiras páginas web e caracterizada pela ocupação de $100 \%$ do ecrã com fontes tamanho 12, onde a estrutura gráfica era muito longa.

A segunda fase, ou "Fase multimídia", foi marcada pelas imagens em movimento, chamadas de gifs, que tiravam a atenção do utilizador da informação principal. Os programadores diversificavam as cores, muitas vezes com padrões de fundos, dificultando a leitura dos textos. Os webmasters aprenderam a integrar diversos meios e, com isso, na maior parte dos sites, começou a surgir alguns fóruns temáticos que passaram a valorizar mais comunicação do que informação.

Na terceira fase, considerada por Carvalho (2006) como a "Fase do design gráfico e interatividade", verifica-se que os webmasters estavam mais sensíveis à importância da simplicidade e da sobriedade. Nessa fase, os gifs animados eram usados quando pertinentes. As 
páginas deixaram de ter vários elementos que "gritavam” pela atenção do utilizador. A forma como a informação é apresentada, agora, é mais convidativa à leitura. Foi nessa fase que as ferramentas de comunicação diversificaram-se e intensificaram-se. O correio eletrônico, o chat e os fóruns temáticos contribuíram certamente para o aparecimento de comunidades de aprendizagem. Em meados da década de 1990, iniciou-se a quarta fase que tem como prioridade a edição colaborativa online. Além disso, os conteúdos midiáticos diversificaram-se, embora ainda predomine o texto escrito.

Os sites atuais costumam ter informação organizada para os diferentes tipos de público. Redes sociais, blogs e websites possuem exigências e necessidades distintas, tais como seus utilizadores que podem se encontrar em sessões de chat, em sistemas de mensagens em tempo real com áudio e/ou vídeo, no correio eletrônico e fóruns. São ferramentas que contribuem para intensificar a comunicação. Com isso, o volume de informação cresceu e obrigou as instituições a adotarem táticas de gestão da informação e dos conteúdos produzidos.

Os conteúdos, para serem publicados e compartilhados, requerem especial atenção às linguagens de programação que utilizam. O nível de complexidade é alto e às vezes inacessível para alguns. Surge, então, na década de 1990, os sistemas de gestão de conteúdos (CMS - Content Management System) que, para Barcia (2008), é uma plataforma que integra ferramentas que permitem criar e publicar conteúdo em tempo real, onde os usuários utilizam uma interface intuitiva e dinâmica, sem a necessidade de uma programação específica.

Não obstante dessa definição, Bax e Pereira (2002) definem CMS como sendo um sistema que permite a qualquer utilizador da internet, mesmo àqueles com poucos conhecimentos em informática, gerir um website dinâmico no qual o conceito estruturante do CMS é separar a gestão de conteúdos do design gráfico das páginas.

Segundo Bax e Pereira (2002),

Os CMS dispõem de duas áreas distintas: uma pública para consulta de conteúdos (Frontend); uma restrita aos gestores da informação para inserção/gestão de conteúdos e gestão da própria estrutura (Backend). Além disso, incluem um vasto conjunto de ferramentas que possibilitam, de uma forma estruturada e célere, a inserção de diversos tipos de conteúdos (BAX; PEREIRA, 2002, p. 1).

Os autores acrescentam, ainda, que gerir conteúdo na web é utilizar conceitos e ferramentas que visam amenizar os problemas característicos da produção e da manutenção de conteúdos em sítios web. Tramullas (2005) define conteúdo como um objeto que representa virtualmente o documento no ambiente digital.

Dessa forma, vimos que a gestão de conteúdos é um processo que permite coletar, preparar, qualificar e estruturar recursos de informação, de qualquer tipo ou formato, de modo a serem guardados, recuperados, publicados, atualizados e usados para outros fins. 


\section{O SISTEMA DE GESTÃO DE CONTEÚDOS JOOMLA E SUAS FERRAMENTAS DE MÍDIA}

Segundo a Comunidade Joomla Portuguesai, a designação Joomla para o software é a transcrição fonética para a palavra Swahili “Jumla", que significa "todos juntos” ou "sob a forma de um todo". Essa palavra é de origem árabe, usualmente entendida como "total” ou "soma" e devido à influência dos comerciantes árabes.

Para Rahmel (2010), o Joomla é uma das ferramentas CMS mais utilizadas devido sua facilidade de uso, as características profissionais e a interface intuitiva que contribuem contribuem para sua aceitação por instituições empresariais e educacionais. Já para Lima e Ribeiro (2010), o Joomla é hoje um dos CMS open source - desenvolvidos em PHP (acrônimo de Hipertext Preprocesor) - mais populares. A ferramenta surgiu a partir do projeto Mambo, CMS desenvolvido pela Miro, companhia sediada em Melbourne, na Austrália. Problemas internos fizeram com que parte da equipe abandonasse o projeto e, a partir daí, em setembro de 2005, surgiu um novo gerenciador de conteúdo, o Joomla.

Em sua dissertação de mestrado, apresentada à Universidade Católica Portuguesa, Barcia (2008) fez um estudo sobre o "Uso da plataforma Joomla na Escola”. O pesquisador teve como foco as potencialidades dessa plataforma e concluiu que existem vários CMS, mas que o Joomla é o mais simples de se utilizar, pois é completo em termos de funcionalidades, sendo considerado pelos professores participantes no estudo uma solução viável a ser utilizada na construção de portais educativos.

Nesse contexto, Rahmel (2010) afirma que uma das principais características do Joomla é a variedade de interfaces personalizadas fáceis de serem usadas e seus suportes adicionais tais como: fóruns, comunidades online, chats, artigos, vídeos e redes sociais. Tudo isso é disponibilizado gratuitamente e não há a necessidade de um programador.

Esses suportes, segundo Levy (1993), quando parte de sistemas educativos e de documentação, podem ser chamados de hipermídia, como um subproduto do hipertexto, deixando claro que não exclui de forma alguma a dimensão audiovisual.

\footnotetext{
Tecnicamente, um hipertexto é um conjunto de nós ligados por conexões. Os nós podem ser palavras, páginas, imagens, gráficos ou partes de gráficos, sequências sonoras, documentos complexos que podem eles mesmos ser hipertextos. (...) Funcionalmente, um hipertexto é um tipo de programa para a organização de conhecimentos ou dados, a aquisição de informações e a comunicação (LEVY, 1993, p. 33).
}

Levando em conta a definição de hipertexto adotada, que alega que as informações podem ser classificadas em texto, imagens, vídeos e sons, nos reportaremos ao Joomla pra identificar essas particularidades no sistema de Gestão de Conteúdos.

De acordo com Rahmel (2010, p. 4), a facilidade de uso do Joomla é equiparada somente às suas características profissionais embutidas. Além do conjunto de características próprias do Joomla, a comunidade de usuário ${ }^{\text {ii }}$ disponibiliza extensões, componentes e plugins gratuitos para os utilizadores. Essa grande quantidade de extensões torna possível gerenciar qualquer tipo de site, com qualquer tipo de conteúdo, seja ele informacional, comercial, educacional ou de redes sociais, salas de bate papo, leilões online, entre outros. 
O poder e a simplicidade do Joomla podem ser difíceis de entender caso não se tenha experiência com CMS. Contudo, qualquer webmaster pode ver que as características administrativas incluídas são convincentes. Rahmel (2010, p. 5) enumera as principais características desse CMS:

- Administração completa feita por meio de uma interface online;

- Administração online das propriedades do site, tais como gráficos, arquivos e outras mídias (Troca da interface através do uso de Templates);

- Aprovação de conteúdo que permite a moderação de posts de autores remotos;

- Gerenciamento hierárquico de grupos de usuários;

- Gerenciamento automatizado de menu;

- Agendamento da publicação de conteúdos e remoção de artigos;

- Gerenciamento de postagem de contribuições online; e

- Interação com os visitantes do site.

Para Rahmel (2010, p. 5), as capacidades de conteúdo do Joomla incluem:

- Editores WYSIWYG embutidos (acrônimo para: What You See Is What You Get ou, o que você é o que você obtém), para os conteúdos;

- Estrutura hierárquica de conteúdos com Secções e Categorias;

- Busca automática de texto completo no conteúdo do site; conteúdo do artigo;

- SEF (search engine-friendly URLs - Motores de busca amigáveis) opcional ao

- Suporte completo para newsfeed (fonte de notícias);

- Enquetes embutidas;

- Administração de banners de propaganda;

- Características multi-idiomas;

- Opções de acessibilidade para deficientes;

- Licença completa de código aberto com download gratuito do aplicativo e código;

- Disponível na maioria dos sistemas operacionais (Windows, Mac OS e Linux); e

- Page caching para um melhor desempenho.

Segundo Barcia (2008), ainda podem ser integradas outras funcionalidades uma vez que existem inúmeros componentes e módulos.

O Sistema de Gestão de Conteúdos Joomla se mostra bastante completo, em termos ferramentais, na produção de conteúdos. Contudo, tais ferramentas requerem estudos mais detalhados para sua utilização em sites educacionais e produção de conteúdos de aprendizagem. 


\section{O PAPEL DO PROFESSOR DIANTE DAS TECNOLOGIAS ATUAIS}

As evoluções tecnológicas contemporâneas estão fortemente ligadas à educação. Segundo Kenski (2003), “[é] impossível educar sem a mediação tecnológica”. Essa pesquisadora diz que as novas tecnologias de informação e comunicação já estão estabelecidas em quase todos os espaços sociais e culturais contemporâneos. Contudo, essa evolução não produz, por si só, as habilidades necessárias à elaboração e sistematização de novos conhecimentos. O ensino que se utiliza da informática exige competências científicas e pedagógicas do professor. Conforme Moran (2003), os modelos educacionais convencionais mantém distantes professores e alunos.

Para Morais (1996), no paradigma educacional condizente com a atualidade, a ênfase está no processo de aprendizagem pelo qual os educandos desenvolverão características próprias como "criticidade, criatividade, autonomia, imaginação, raciocínio, construção do seu conhecimento, pesquisa e conhecimento existente, adaptabilidade ao novo conhecimento integrando interdisciplinaridade e cooperação”.

Segundo Mercado (1999, p. 80), o professor será o “agente que estimulará a relação dos alunos com a rede, será o facilitador, será o desafiador, o facilitador, o coordenador dos trabalhos para que os objetivos não se percam antes de serem atingidos”.

De acordo com Moran (2000, p. 11), “todos estamos experimentando que a sociedade está mudando nas suas formas de organizar-se, de produzir bens, de comercializá-los, de divertir-se, de ensinar e de aprender”. Esse autor afirma também que, hoje, as formas de ensinar não se justificam mais, pois se perde muito tempo e aprende-se pouco, o que nos desmotiva continuamente.

Levy (1999) sintetiza o novo papel do professor, no contexto atual, como sendo o animador da inteligência coletiva dos grupos que estão ao seu encargo. Afirma também que as atividades dos professores serão centradas no acompanhamento e na gestão das aprendizagens por meio de incentivo às trocas de saberes, da mediação relacional e do acompanhamento dos percursos da aprendizagem.

Numa proposta metodológica que se utiliza da internet, Moran (2000, p. 45) sugere que “o professor crie uma página pessoal na internet, como espaço virtual de encontro e divulgação, um lugar de referência para cada aluno”. Afirma ainda que "[e]ssa página pode ampliar o alcance do professor, de divulgação de suas ideias e propostas, contatos com pessoas fora da universidade e escola”.

Sem desprezar essa proposta e indo um pouco mais além, sugere-se então que se convertam as ideias de diário - a que nos remete o blog - para informações mais consistentes e selecionadas. Assim chegamos à noção de portal.

Segundo Souza (2008),

Os portais foram criados com o objetivo de fornecer aos usuários um suporte para sua navegação e reunir num mesmo site tudo que poderia ser importante como informação, email, chat, notícias, mecanismos de busca, etc. Os usuários, desta forma, não precisariam recorrer a outras páginas e restringiriam sua busca àquele espaço (SOUZA, 2008, p. 116). 
O mesmo autor afirma também que, nesses tipos de atividades, é necessário que haja grupos de pessoas que discutam determinados assuntos, quer específicos ou genéricos, ação mediada, ou não, por um professor ou animador da coletividade.

Apesar das várias possibilidades de inovações no processo de aprendizagem com o uso das novas tecnologias educacionais, como complemento do conteúdo disciplinar, é exigida uma disponibilidade maior do tempo do professor. O professor, como autor do material didático, terá que fazer adaptações do conteúdo à comunicação visual via rede. Em alguns momentos, ele terá que exercer o papel de ator, quando lança mão de gravações em vídeo e DVD, transmissões televisivas ou acopladas ao site.

No contexto atual, a produção do material didático amplia-se em possibilidades ao agregar mais recursos mediadores devido a grande capacidade de armazenamento, bem como a possibilidade de reprodução de vídeos, som, imagens e material impresso.

Pode-se também criar, pela internet, uma cooperativa que favoreça e fortaleça o trabalho conjunto entre professores e alunos, próximos física ou virtualmente. Para Moran (2000), uma forma interessante de se trabalhar colaborativamente é criar uma página dos alunos, com um espaço virtual de referência, aonde se vai construindo e colocando o que acontece de mais importante no curso, como os textos, os endereços, as análises e as pesquisas. Pode ser um site provisório, interno, sem divulgação, que, eventualmente, possa ser colocado à disposição do público externo.

Como Moran (2000) observa, neste processo dinâmico muda a relação de espaço, tempo e comunicação do professor com os alunos. O espaço aumenta da sala de aula para o virtual. O tempo de enviar ou receber informações é ampliado para qualquer dia e qualquer hora. A comunicação também acontece a qualquer momento, podendo ser em sala de aula, na internet, no $e$ mail, no chat. Nesse processo, é importante integrar as dinâmicas tradicionais com as inovadoras, o texto sequencial com o hipertexto, o encontro presencial com o virtual. Nas palavras do autor,

O que muda no papel do professor? (...) É um papel que combina alguns momentos do professor convencional - às vezes é importante dar uma bela aula expositiva - com mais momentos de gerente de pesquisa, de estimulador de busca, de coordenador dos resultados, É um papel de animação e coordenação muito mais flexível e constante, que exige muita atenção, sensibilidade, intuição (radar ligado) e domínio tecnológico (MORAN, 2000, p. 20).

O professor, tendo uma visão pedagógica inovadora, aberta, que pressupõe a participação dos alunos, pode utilizar algumas ferramentas simples da internet para melhor interação presencial ou virtual entre professor-aluno-colegas.

Filatro (2008, p. 1) traz à cena um novo profissional, o designer instrucional, afirmando que se trata de "um conjunto de atividades para identificar um problema de aprendizagem e desenhar, implementar e avaliar uma solução” .

Segundo essa autora,

A ação intencional e sistemática de ensino que envolve o planejamento, o desenvolvimento e a aplicação de métodos, técnicas, atividades, eventos e produtos educacionais em situações didáticas específicas, a fim de promover, a partir dos princípios de aprendizagem e instruções conhecidos, a aprendizagem humana (FILATRO, 2008, p. 1). 
Nesse viés, a produção do material didático exige um repensar pedagógico, incluindo a criação de estratégias didático-pedagógicas para uma efetiva aprendizagem em uma nova configuração, onde a mídia deve ser utilizada como apoio a um processo planejado presencialmente e executado virtualmente.

\section{CONSIDERAÇÕES FINAIS}

Vimos através deste estudo que, ao longo do tempo, os websites evoluíram no nível de layout das páginas, na estruturação da informação e na integração de ferramentas de comunicação e de edição colaborativa online. Essa evolução forçou as instituições a adotarem táticas de gestão da informação e dos conteúdos produzidos. Dessa necessidade, surgiram os Sistemas de Gestão de Conteúdos que permitem qualquer usuário com privilégios administrativos gerir um website dinâmico, criar e publicar conteúdos em tempo real através de uma interface intuitiva e dinâmica.

O Sistema de Gestão de Conteúdo (CMS) Joomla demonstra ser o mais completo em termos de funcionalidades e com maior número de componentes. Além disso, possui uma variedade de interfaces personalizadas e com suportes adicionais para fóruns, comunidades online, chats, artigos, vídeos e redes sociais.

As principais características do Joomla são as extensões, componentes e módulos, entre outras funcionalidades, dependendo da necessidade da instituição que escolhe esses Sistemas de Gestão. Assim, os paradigmas atuais tendem a manter distantes professores e alunos. Mas o professor tem um papel de agente animador centrado no acompanhamento da gestão das aprendizagens através do incentivo às trocas de saberes e da mediação relacional. A construção de um portal educacional para este fim ampliaria o alcance do professor e, teoricamente, levaria a aula para fora do espaço físico da escola.

As inovações tecnológicas utilizadas hoje podem não resolver os problemas da educação, sociedade, política e ideológica, mas, com certeza, se utilizada como suporte ao sistema de ensino atual, pode melhorar a qualidade do mesmo e, consequentemente, qualificar melhor os alunos e a sociedade na busca da perfeição educacional.

\section{REFERÊNCIAS BIBLIOGRÁFICAS}

BARCIA, L. M. G. A utilização da plataforma joomla! na escola. 2008. Dissertação (Mestrado em Ciências da Educação). Universidade Católica Portuguesa, 2008.

BAX, M. P.; PEREIRA, J. C. Introdução à Gestão de Conteúdos. $3^{\circ}$. Workshop Brasileiro de Inteligência Competitiva e Gestão do Conhecimento, 2002, São Paulo. Anais... $1^{\circ}$. Congresso Anual da Sociedade Brasileira de Gestão do Conhecimento.

FILATRO, A. Design instrucional contextualizado: educação e tecnologia. Editora Senac. São Paulo, 2004.

KENSKI, V. M. Tecnologias do Ensino Presencial e a Distância. Campinas, SP Papirus, 2003. (Série prática pedagógica). 
LÉVY, P. A Inteligência coletiva: por uma antropologia do ciberespaço. São Paulo: Loyola, 1998. LÉVY, P. O que é o virtual? Rio de Janeiro: Ed. 34, 1996.

LÉVY, P. Cibercultura. São Paulo: Ed. 34, 1999.

LIMA, A. L. A.; RIBEIRO; R. R. CMS: Disponibilidade, praticidade e economia, estudo comparativo Joomla, Drupal e WordPress. Disponível em: < $\underline{\text { http://www.fatecjp.com.br/revista/art- }}$ ed02-003.pdf>. Acesso em 02 nov. 2010.

MORAN, José Manuel. Novas Tecnologias, Mediação Pedagógica / José Manuel Moran, Marcos T. Masseto, Marilda Aparecida Behrens - Campinas SP: Papirus, 2000. (Coleção Papirus Educação).

MORAIS, M. C. O Paradigma Emergencial: implicações na formação do professor e nas práticas pedagógicas. Em aberto, Brasília, n.16, abr./jun. 1996. p. 57-69.

RAHMEL, D. Dominando Joomla: do Iniciante ao Profissional. Trad. 2. ed. Rio de Janeiro: Alta Books Editora. 2010

SOUZA, C. H. M.; GOMES, M. L. M. Educação e Ciberespaço. 1. ed. Brasília: Editora Usina de Letras, 2008. 158p.

TRAMULLAS, J. (2005). Herramientas de software libre para la gestión de contenidos.

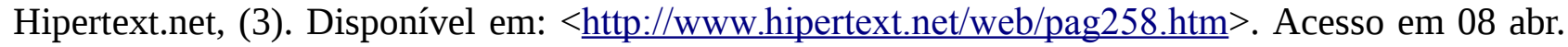
2011. 
i Comunidade joomla portuguesa: $<$ http://www.joomlapt.com/sobre-o-joomla/nome-e-marca-joomla.html $>$. ii $<$ http://www.joomla.org.br $>$. 